\title{
Salinidade na água de beber de ovinos e uso dos dejetos em cultivo de plântulas de milho
}

\author{
Salinity in the drinking water of sheep and use of their manure for cultivation \\ of maize seedlings
}

\author{
Nilmara Mércia de Souza Sá Santos ${ }^{\mathrm{I}}$ Mário Adriano Ávila Queiroz ${ }^{\text {I* }}$ \\ Gherman Garcia Leal de Araújo ${ }^{\mathrm{II}}$ Samir Augusto Pinheiro CostaI \\ Ítalo Reneu Rosas de Albuquerque ${ }^{\mathrm{III}}$ José Helder Andrade Moura ${ }^{\mathrm{II}}$ \\ Marlon da Silva Garrido ${ }^{I}$ Daniel Bomfim Manera ${ }^{\mathrm{I}}$
}

RESUMO

O objetivo deste estudo foi caracterizar substratos e avaliar a emergência e a sobrevivência de sementes de milho, bem como o crescimento, massa seca da parte aérea e a massa seca da raiz de plântulas cultivadas com substratos (solo e dejetos de ovinos), alimentados com água com diferentes níveis de sólidos dissolvidos totais (SDT)- 640; 3.188; 5.740 e 8.326mgl. O estudo foi desenvolvido em casa de vegetação no setor de produção de mudas da Embrapa Semiárido em Petrolina-PE. O delineamento experimental utilizado foi o inteiramente casualizado, com quatro tratamentos e dez repetições. Os dados foram analisados por meio de contrastes ortogonais e regressão polinomial. Foi verificado efeito $(P<0,05)$ no índice de velocidade de emergência, sendo estimado por regressão que o melhor substrato deva conter até 1811SDT na água de beber dos animais para essa variedade de milho. No entanto, na biomassa da parte aérea e da raiz, o percentual de sobrevivência e altura das plântulas não sofreram modificações $(P>0,05)$.

Palavras-chave: dejetos, salinidade, Zea mays.

\section{ABSTRACT}

The objective of this study was to characterize and to evaluate the emergence and survival of maize seeds, as well as growth, dry mass of shoot and root dry mass of seedlings grown with manure of sheep fed with water with different levels of total dissolved solids (TDS) -640, 3188, 5740 and $8326 \mathrm{mg}^{-1}$. The study was conducted in the greenhouse industry seedling production at Embrapa Semi-Arid in Petrolina-PE. The experimental design was completely randomize with four treatments and ten replicates. Data were analyzed using orthogonal contrasts and polynomial regression. It was significant $(P<0.05)$ in the rate of emergence estimated by regression that the best substrate should contain until 1811 SDT in drinking water for this variety of corn. However, the biomass of shoot and root, the percentage of survival and seedling height have not been changed $(P>0.05)$.

Key words: salinity, waste, Zea mays.

\section{INTRODUÇÃO}

O solo da região Nordeste do Brasil é constituído por mais de $70 \%$ de rochas cristalinas, fato que promove a predominância de águas subterrâneas com elevado teor de sais, impossibilitando o consumo humano deste recurso (ANA, 2010). Tanto agricultores quanto caprinovinocultores do semiárido destinam as águas salinas captadas em poços ao consumo animal devido à capacidade que os ovinos e caprinos apresentam de adaptação às altas concentrações de sais, seguida de maior ingestão e consequente excreção nas fezes e urina (MCGREGOR, 2004). As concentrações de minerais presentes nos dejetos podem influenciar diretamente nas características do solo, acarretando incrementos ou impactos negativos na produção vegetal, a depender da adaptabilidade da cultura à salinidade (GOMES, 2005).

O milho é um dos cereais mais cultivados no mundo, com uma produção média de 778,8 milhões de toneladas nos últimos cinco anos (DEMARCHI, 2011). Destaca-se por desempenhar papel socioeconômico pelas suas diversas formas de utilização, que variam da alimentação humana e animal à indústria de alta tecnologia como geração

'Programa de Pós-graduação em Ciência Animal, Universidade Federal do Vale do São Francisco (UNIVASF), 56300-000, Petrolina, PE, Brasil. E-mail: mario.queiroz@univasf.edu.br. *Autor para correspondência.

"Embrapa Semiárido, Petrolina, PE, Brasil.

"II Universidade Federal da Paraíba (UFPB), Areia, PB, Brasil. 
de energia. O uso do milho na alimentação humana é representado pelo consumo de seus derivados, principalmente nas regiões de baixa renda, como é o caso da região Nordeste do Brasil, em que o milho é fonte de nutrientes para pessoas que vivem em áreas rurais do semiárido (CRUZ, 2011).

Devido à grande importância do milho, têm-se buscado alternativas aos modelos produtivos convencionais que possibilitem diminuir os custos de produção. Uma delas é a utilização da adubação orgânica, que tem se destacado pela sua potencialidade na fertilização do solo, devido ao seu elevado teor de matéria orgânica e a presença de nutrientes essenciais às plantas. Sua utilização tem sido vista como opção para redução dos custos de produção, substituindo, em parte ou totalmente, os fertilizantes minerais (CERETTA et al., 2005).

Alguns estudos avaliaram o potencial de utilização do esterco de caprinos e ovinos na produção de milho e todos ressaltam seu valor nutricional (ALVES \& PINHEIRO, 2008; ARAUJO, 2010). Entretanto, poucos dados existem na literatura quanto ao seu uso na produção orgânica, quando oriundo de animais alimentados com águas salinas.

Nesse contexto, a adubação utilizada para a germinação das sementes e emergência das plântulas constitui uma das etapas primordiais para a implantação dos cultivos comerciais, sendo responsável pelo estabelecimento da população desejada e consequente rendimento final da lavoura. Além disso, o sucesso do cultivo comercial de milho varia em função de alguns fatores agronômicos, dentre os quais a adubação, que influencia na composição de carboidratos, favorecendo a osmose de minerais e facilitando a absorção de água pela semente (PRIMAVESI, 1990).
Segundo NEGREIROS et al. (2004), um bom substrato é aquele que proporciona condições adequadas à germinação e ao desenvolvimento do sistema radicular da muda em formação. Considerando que tanto a germinação quanto o desenvolvimento das mudas requerem água, oxigênio e suporte físico, um bom substrato deve proporcionar adequado equilíbrio entre umidade e aeração, além de disponibilizar aquisição e transporte de nutrientes essenciais e apresentar $\mathrm{pH}$ adequado; características apresentadas pelos dejetos de ovinos e caprinos.

Portanto, objetivou-se com este estudo avaliar o efeito da salinidade da água de beber de ovinos sobre seus dejetos quando da caracterização de substratos e cultivo de plântulas de milho, por meio da avaliação das variáveis fisiológicas: velocidade de emergência, percentual de germinação, crescimento, massa seca da parte aérea e massa seca da raiz.

\section{MATERIAL E MÉTODOS}

O experimento foi conduzido nos meses de março e maio de 2011 em casa de vegetação no setor de produção de mudas, pertencente à Empresa Brasileira de Pesquisa Agropecuária - Embrapa Semiárido, localizada no município de Petrolina-PE, situada na região Nordeste do país. A região encontrase a 300 metros de altitude acima do nível do mar, com temperatura média de $27,0^{\circ} \mathrm{C}$ e umidade relativa do ar média de $78 \%$ no período experimental, determinados por leituras diárias da temperatura de Bulbo Seco, temperatura de Bulbo Úmido e Umidade Relativa.

Foram avaliados os substratos 1, 2, 3 e 4, compostos por esterco de ovinos Morada Nova (Tabela 1), oriundo de experimento com 32 animais

Tabela 1 - Quantidades de fósforo $(\mathrm{P})$, potássio $(\mathrm{K})$, cálcio $(\mathrm{Ca})$, magnésio $(\mathrm{Mg})$, enxofre $(\mathrm{S})$, cobre $(\mathrm{Cu})$, ferro $(\mathrm{Fe})$, manganês $(\mathrm{Mn})$, zinco (Zn) e sódio $(\mathrm{Na})$ do esterco, de acordo com os diferentes níveis de Sólidos Dissolvidos Totais.

\begin{tabular}{|c|c|c|c|c|c|}
\hline \multirow{2}{*}{ Mineral } & \multirow{2}{*}{ Unidade } & \multicolumn{4}{|c|}{ 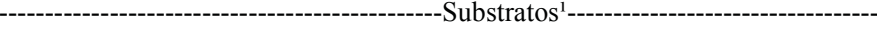 } \\
\hline & & 1 & 2 & 3 & 4 \\
\hline $\mathrm{P}$ & Cmolc dm ${ }^{-3}$ & 5,1 & 4,7 & 4,6 & 4,6 \\
\hline $\mathrm{K}$ & Cmolc dm ${ }^{-3}$ & 10,0 & 12,0 & 8,3 & 9,3 \\
\hline $\mathrm{Ca}$ & Cmolc dm ${ }^{-3}$ & 8,5 & 9,8 & 8,5 & 8,6 \\
\hline $\mathrm{Mg}$ & Cmolc dm ${ }^{-3}$ & 3,0 & 3,1 & 2,9 & 2,9 \\
\hline $\mathrm{S}$ & Cmolc dm ${ }^{-3}$ & 3,1 & 2,8 & 2,8 & 2,7 \\
\hline $\mathrm{Cu}$ & $\mathrm{mg} \mathrm{dm}{ }^{-3}$ & 19,7 & 15,0 & 16,3 & 18,7 \\
\hline $\mathrm{Fe}$ & $\mathrm{mg} \mathrm{dm}{ }^{-3}$ & 6566,7 & 4833,3 & 4900,0 & 4000,0 \\
\hline $\mathrm{Mn}$ & $\mathrm{mg} \mathrm{dm}{ }^{-3}$ & 258,3 & 251,7 & 243,7 & 275,0 \\
\hline $\mathrm{Zn}$ & $\mathrm{mg} \mathrm{dm}{ }^{-3}$ & 136,0 & 105,7 & 105,0 & 117,7 \\
\hline $\mathrm{Na}$ & Cmolc dm ${ }^{-3}$ & 2615,4 & 4060,7 & 5001,9 & 5136,4 \\
\hline
\end{tabular}

${ }^{1}$ Substrato 1- Fonte: 8 ovinos alimentados com 640SDT na água; Substrato 2- Fonte: 8 ovinos alimentados com 3.188SDT na água; Substrato 3- Fonte: 8 ovinos alimentados com 5.740SDT na água; Substrato 4- Fonte: 8 ovinos alimentados com 8.326SDT na água. 
confinados em baias individuais, durante 63 dias, alimentados com água em diferentes níveis de sólidos dissolvidos totais (SDT) - 640; 3.188; 5.740 e $8.326 \mathrm{mg}^{-1}$, com oito animais por tratamento. Os diferentes níveis de salinidade foram obtidos adicionando-se $\mathrm{NaCl}$ à água em reservatórios com capacidade para 500 litros e aferidos por condutivímetro portátil digital em amostra previamente homogeneizada. Os valores de condutividade elétrica ( 1-5-9 e 13) foram convertidos em sólidos dissolvidos totais. A dieta utilizada era composta por $50 \%$ de concentrado a base de farelo de milho e soja com $18,49 \%$ de proteína bruta (PB), $15,43 \%$ de fibra em detergente neutro (FDN), 5,71\% de matéria mineral (MM) e $50 \%$ de feno de capimbuffel (Cenchrusciliares) com 4,81\% de PB, 75,14\% de FDN e 11,6\% de MM. O esterco foi composto de fezes e urina, recolhidos diretamente do piso das baias dos oito animais pertencentes ao mesmo tratamento, durante cinco dias aleatórios, constituindo as quatro diferentes fontes de esterco: substrato 1-fonte: nível 640 SDT; substrato 2- fonte: nível 3.188SDT; substrato 3- fonte: nível 5.740SDT e substrato 4-fonte: nível 8.326SDT. Após o recolhimento, os estercos foram homogeneizados, umedecidos com água e cobertos com lona plástica de polietileno durante vinte dias, a fim de facilitar o processo de fermentação. Posteriormente, foi desidratado ao sol, peneirado e moído.

Foram utilizadas três sementes de milho (Zea mays L.), cultivar caatingueiro, por saco de polietileno, com dimensões de 10x18x8cm, dez sacos por tratamento, cultivadas a uma profundidade de $3 \mathrm{~cm}$ e irrigadas a cada dois dias com $50 \mathrm{ml}$ de água destilada. A proporção do substrato utilizado foi de $2: 1$, sendo dois litros de solo e um litro de esterco.

As análises do esterco, solo e substrato (solo mais esterco), conforme apresentado nas tabelas 1 e 2, foram realizadas no Laboratório de Análises de Solos da Embrapa Semiárido, segundo MALAVOLTA (1997), que consiste em extrair da matéria seca minerais por digestão ácida quente, seca e agitação, com determinação por meio de espectrofotometria por absorção atômica e ótica.

O período experimental teve duração de 15 dias (CONCEIÇÃ̃O et al., 2012), sendo acompanhado o início e estabilização da emergência das plântulas e feita leitura da altura delas ao décimo quinto dia de cultivo, medindo-se com régua graduada do colo das plântulas ao ápice da última folha emitida. Ao término do período de avaliação, a parte aérea das plântulas foi cortada ao nível do solo, armazenada em sacos de papel e encaminhada para estufa de ventilação forçada de ar a $55^{\circ} \mathrm{C}$ por 72 horas. Após a retirada da parte aérea, foram obtidas as raízes através do corte dos sacos de polietileno e destorroamento do solo, sendo as raízes colocadas em sacos de papel e, em seguida, encaminhadas para estufa de ventilação forçada de ar a $55^{\circ} \mathrm{C}$ por 72 horas.

$\mathrm{O}$ índice de velocidade de emergência foi determinado com a contagem diária das plântulas emergidas e calculado pela fórmula proposta por MAGUIRE (1962):

$\operatorname{IVE}=\mathrm{E}_{1} / \mathrm{N}_{1}+\mathrm{E}_{2} / \mathrm{N}_{2}+\ldots+\mathrm{E}_{\mathrm{n}} / \mathrm{N}_{\mathrm{n}}$ em que:

IVE - Índice de Velocidade de Emergência;

$\mathrm{E}_{1}, \mathrm{E}_{2}$ e En - Número de sementes emergidas computadas na primeira contagem, na segunda contagem e na última contagem;

$\mathrm{N}_{1}, \mathrm{~N}_{2}$ e $\mathrm{N}_{\mathrm{n}}$ - Número de dias da semeadura a primeira, a segunda e a última contagem.

A média de porcentagem de germinação por tratamento foi calculada de acordo com LABOURIAU \& VALADARES (1976):

$\mathrm{G}=(\mathrm{N} / \mathrm{A}) \cdot 100$

em que:

$\mathrm{G}$ - germinação.

$\mathrm{N}$ - número total de sementes germinadas.

A - número total de sementes colocadas para germinar. $\mathrm{O}$ delineamento experimental utilizado foi o inteiramente casualizado, com quatro tratamentos e dez repetições. Os resultados foram analisados pelo programa computacional Statistical Analysis System (Versão 9.1, 2003), sendo anteriormente verificada a normalidade dos resíduos pelo Teste de SHAPIROWILK (PROC UNIVARIATE) e as variâncias comparadas por contrastes ortogonais PROC GLM e regressão polinomial PROC REG, com nível de significância de $5 \%$.

\section{RESULTADOS E DISCUSSÃO}

Os resultados da análise de variância revelaram efeito de tratamento $(\mathrm{P}<0,05)$ sobre a concentração de sódio $(\mathrm{Na})$ nos substratos, bem como para o potencial hidrogeniônico $(\mathrm{pH})$, concentração de potássio $(\mathrm{K})$, concentração de ferro $(\mathrm{Fe})$ e Capacidade de Troca Catiônica (CTC) (Tabela 3). Os substratos 1 e 2 (Tabela 3) apresentaram tendência a maiores concentrações de Matéria Orgânica (MO), apesar de não ter sido verificada diferença $(\mathrm{P}>0,05)$; o substrato 3, mesmo apresentando CTC superior ao substrato 1 e 4, apresentou maior concentração de MO do que o substrato 4, o que poderia explicar os melhores resultados dos substratos 1,2 e 4 no Índice de Velocidade de Emergência (IVE), associado à suas maiores concentrações de potássio (K) (Tabela 3). Tais resultados corroboram o processo observado 
por SANTOS (2009) em referência a estudo com uso de diferentes doses de esterco em cultivo de milho, no qual afirma que o uso de matéria orgânica em adubação promove aumento na CTC, evitando perdas por lixiviação, melhorando a agregação, diminuindo a oscilação de temperatura do solo e ajudando na liberação dos nutrientes à planta. Os resultados foram semelhantes aos observados por RODRIGUES et al. (2011) que, estudando o efeito do húmus de minhoca peletizado e do fertilizante mineral na cultura do milho, observaram que os incrementos de matéria orgânica das amostras com húmus foram similares aos do fertilizante mineral, sugerindo a possível substituição e redução de custos na produção.

Os níveis médios de sódio encontrados nos substratos (Tabela 3) revelam que houve salinização gradativa do solo, quando comparados aos valores de sódio descritos na tabela 2 , devido provavelmente às concentrações de $\mathrm{Na}$ dos estercos (Tabela 1). Consequentemente, ocorreu a alcalinização decrescente do solo, presente em todos os substratos, observada pela diminuição do $\mathrm{pH}$. O $[\mathrm{Na}]+$ é essencial para plantas com mecanismo de fotossíntese $\mathrm{C}_{4}$, como é o caso do milho, pois ele é responsável por regenerar o fosfoenolpiruvato, que se liga ao $\mathrm{CO}_{2}$, iniciando a fixação de carbono. No entanto, o excesso desse íon pode provocar efeitos tóxicos (FAQUIN,
2005). O milho é considerado moderadamente sensível à salinidade (MANCUSO, 2003).

Apesar do efeito quadrático $(\mathrm{P}<0,05)$, observado para as concentrações de ferro $(\mathrm{Fe})$ nos substratos (Tabela 3), as plântulas não apresentaram sintomas de carência e nem toxidez, provavelmente devido ao fato de o $[\mathrm{Fe}]^{+3}$ ter a sua solubilidade e geoquímica afetadas pelo $\mathrm{pH}$ do solo, uma vez que a sua disponibilidade é maior sob condições de $\mathrm{pH}$ mais baixo (ácido) que os encontrados neste estudo (FAQUIN, 2005).

O potássio $(\mathrm{K})$, por sua vez, é o segundo nutriente mais exigido pelas plantas; as plantas produtoras de amido, açúcar e fibras parecem ser particularmente exigentes em K (FAQUIN, 2005). Segundo MENGEL \& KIRKBY (1987), o pequeno crescimento de plantas deficientes em $\mathrm{K}$ está, obviamente, diretamente relacionado com o efeito do $\mathrm{K}$ sobre a ATPase da plasmalema dos tecidos meristemáticos, além de contribuir para a regulação osmótica da planta, atuar na ativação enzimática e no processo de absorção iônica, o que poderia explicar a diferença entre os substratos 1,2 e 4 e o substrato 3 , observada neste estudo para a variável índice de velocidade de emergência, em função da concentração de $\mathrm{K}$ encontrada nos diferentes substratos.

Com relação às variáveis altura das plântulas e percentual de sobrevivência das sementes

Tabela 2- Composição mineral dos substratos (mistura solo e esterco).

\begin{tabular}{|c|c|c|c|c|c|c|c|c|}
\hline \multirow{2}{*}{ Variáveis $^{1}$} & \multicolumn{4}{|c|}{ 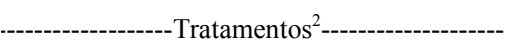 } & \multirow{2}{*}{$\mathrm{EPM}^{3}$} & \multirow{2}{*}{$\mathrm{R}^{2}$} & \multicolumn{2}{|c|}{---------Efeito ${ }^{4}----$} \\
\hline & 1 & 2 & 3 & 4 & & & $\mathrm{~L}$ & $\mathrm{Q}$ \\
\hline Matéria orgânica $\mathrm{g} \mathrm{Kg}^{-1}$ & 105,5 & 99,2 & 93,8 & 70,4 & 6,75 & - & NS & NS \\
\hline Potencial Hidrogeniônico & 8,0 & 7,6 & 7,7 & 7,7 & 0,04 & 97,6 & NS & * \\
\hline Fósforo $\mathrm{mg} \mathrm{dm}^{-3}$ & 340,6 & 436,9 & 302,6 & 319,5 & 16,38 & - & NS & NS \\
\hline Potássio $\mathrm{cmolcdm}^{-3}$ & 3,3 & 3,8 & 2,6 & 3,1 & 0,13 & 96,4 & NS & $*$ \\
\hline Cálcio cmolc $\mathrm{dm}^{-3}$ & 1,9 & 1,6 & 1,6 & 1,8 & 0,07 & - & NS & NS \\
\hline Magnésio cmolc dm ${ }^{-3}$ & 3,7 & 4,5 & 4,2 & 4,4 & 0,11 & - & NS & NS \\
\hline Sódio cmolc dm $\mathrm{dm}^{-3}$ & 1,5 & 3,0 & 4,2 & 4,3 & 0,21 & 98,0 & $*$ & NS \\
\hline Alumínio cmolc $\mathrm{dm}^{-3}$ & 0,4 & 0,4 & 0,3 & 0,4 & 0,01 & - & NS & NS \\
\hline 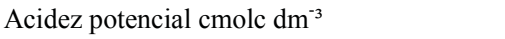 & 0,8 & 1,5 & 1,0 & 1,0 & 0,10 & - & NS & NS \\
\hline Soma bases cmolc $\mathrm{dm}^{-3}$ & 10,2 & 12,8 & 12,1 & 12,0 & 0,29 & - & NS & NS \\
\hline Capacidade de trocas Catalíticas cmolc $\mathrm{dm}^{-3}$ & 11,0 & 14,3 & 13,1 & 13,0 & 0,36 & 93,0 & NS & * \\
\hline Saturação bases \% & 92,7 & 63,0 & 92,0 & 92,7 & 0,64 & - & NS & NS \\
\hline Cobre $\mathrm{mg} \mathrm{dm}{ }^{-3}$ & 1,8 & 1,2 & 1,6 & 1,5 & 0,07 & - & NS & NS \\
\hline Ferro $\mathrm{mg} \mathrm{dm}^{-3}$ & 80,0 & 53,7 & 62,7 & 68,3 & 3,11 & 85,2 & NS & $*$ \\
\hline Manganês $\mathrm{mg} \mathrm{dm}^{-3}$ & 108,7 & 111,7 & 109,3 & 107,3 & 1,28 & - & NS & NS \\
\hline Zinco $\mathrm{mg} \mathrm{dm}^{-3}$ & 15,7 & 16,0 & 14,7 & 13,7 & 0,40 & - & NS & NS \\
\hline
\end{tabular}

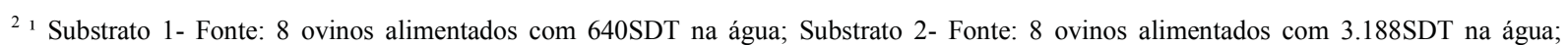
Substrato 3- Fonte: 8 ovinos alimentados com 5.740SDT na água; Substrato 4- Fonte: 8 ovinos alimentados com 8.326SDT na água.

${ }^{3} \mathrm{EPM}=$ Erro padrão da média.

${ }^{4}$ Efeito: Valor de $\mathrm{P}$ para o teste de polinômios ortogonais. L=linear, Q=Quadrático. 
de milho caatingueiro (Tabela 3), cultivadas com substratos oriundos de esterco de animais que ingeriram água com diferentes níveis de salinidade, não foi verificado efeito de tratamento $(\mathrm{P}>0,05)$. Os resultados diferem dos de SANTOS et al. (2009) que, estudando a influência de diferentes doses de esterco sobre o crescimento e desenvolvimento de plantas de milho, obsevaram a influência na variável altura das plântulas, apesar de não haver interferência das doses dos substratos na emergência. Essa diferença foi encontrada por que os autores iniciaram suas avaliações a partir do 15 dias após a emergência (DAE) até $60^{\circ}$ (DAE), nos quais a cultura estava, respectivamente, nos estádios vegetativos (V6, V10, V18) e (R1), na fase reprodutiva. O presente estudo avaliou o crescimento inicial, não encontrando, dessa forma, diferença na variável altura.

$O$ índice de velocidade de emergência (IVE) (Tabela 3) apresentou diferenças entre as médias $(\mathrm{P}<0,05)$, demonstrando efeito de desvio da equação quadrática $\left(\hat{\mathrm{y}}=0,38+0,17 * \mathrm{x}-0,03 * \mathrm{x}^{2}+0,001 * \mathrm{x}^{3} ; \mathrm{r}^{2}=0,43\right)$. Utilizando o procedimento matemático de calcular o $\mathrm{X}$ máximo (Xmax) da equação pela solução Xmax. = $(\mathrm{x} 1) / 2 *(\mathrm{x} 2)$ e substituindo-o na equação de regressão, foi verificado que 2,83 de condutividade elétrica da água de beber ou 1811 de SDT se obtém o melhor substrato para a maior velocidade de emergência $(0,64)$.

O IVE foi mais alto para aqueles tratamentos que continham esterco de animais que ingeriram água com níveis de 640,$0 ; 3.188,0$ e $8.326,0$ SDT, substratos 1,2 e 4, quando comparado com o de 5.740,0 SDT, substrato 3, apresentando valores de 0,$52 ; 0,57 ; 0,52 ; 0,31$, respectivamente, o que mostra que o tempo médio de emergência foi aumentado não pela presença de maiores níveis de $\mathrm{Na}$, mas sim pela deficiência de $\mathrm{K}$, sendo o primeiro dia de germinação em torno de 4 a 5 dias para os substratos 1, 2 e 4; e 7 dias no substrato 3. Esse efeito corrobora os dados apresentados por SANTOS et al. (1992) que, ao estudarem o estresse salino e hídrico na germinação e vigor de sementes de soja, verificaram menores percentagens de germinação para os tratamentos que foram submetidos aos menores potenciais osmóticos da solução de $\mathrm{NaSO}_{4}, \mathrm{CaCl}_{2}$ (-12 -15atm) e $\mathrm{NaCl}$ (-15atm). Segundo SANTOS et al. (1992), a salinidade pode afetar a germinação, pois dificulta a absorção de água pelas sementes e facilita a entrada de íons em níveis tóxicos.

Estudo realizado por BLANCO et al. (2007), avaliando efeito da irrigação de água salina sobre a emergência percentual de milho e soja, verificaram que o milho não sofreu efeito da irrigação até o nível de 5,9 $\mathrm{dS} \mathrm{m}^{-1} \mathrm{de}$ condutividade elétrica na água, efeito significativo encontrado apenas para o cultivo da soja. Esse teor de condutividade é próximo ao obtido na água de bebida fornecida aos animais que contribuíram com o substrato 2 desse experimento, em que não foi encontrada diferença $(\mathrm{P}<0,05)$ na sobrevivência nas plântulas de milho (Tabela3).

Quanto à massa seca da parte aérea (MSPA) e à massa seca da raiz (MSR), não foi observada diferença $(\mathrm{P}>0,05)$ nos diferentes substratos em estudo, conforme tabela 3. Apesar de não ter ocorrido efeito significativo para as variáveis MSPA e MSR, alguns estudos apontam efeito negativo do incremento de salinidade sobre essas variáveis. Segundo ESTEVES \& SUZUKI (2008), há reduções significativas do peso da parte aérea, altura da planta, número de folhas por planta, comprimento de raízes e superfície de raízes por planta devido ao incremento de salinidade. Da mesma forma, CONUS et al. (2009), estudando o crescimento de cultivares de milho com tolerância diferenciada à salinidade, quando submetidas a

Tabela 3 - Índice de velocidade de emergência (IVE), Altura média de plântulas, Sobrevivência de sementes, valores médios de Biomassa da Parte Aérea (BPA), Massa Seca da Parte Aérea (MSPA), Biomassa da Raiz (BRA) e Massa Seca da Raiz (MSRA) de milho caatingueiro.

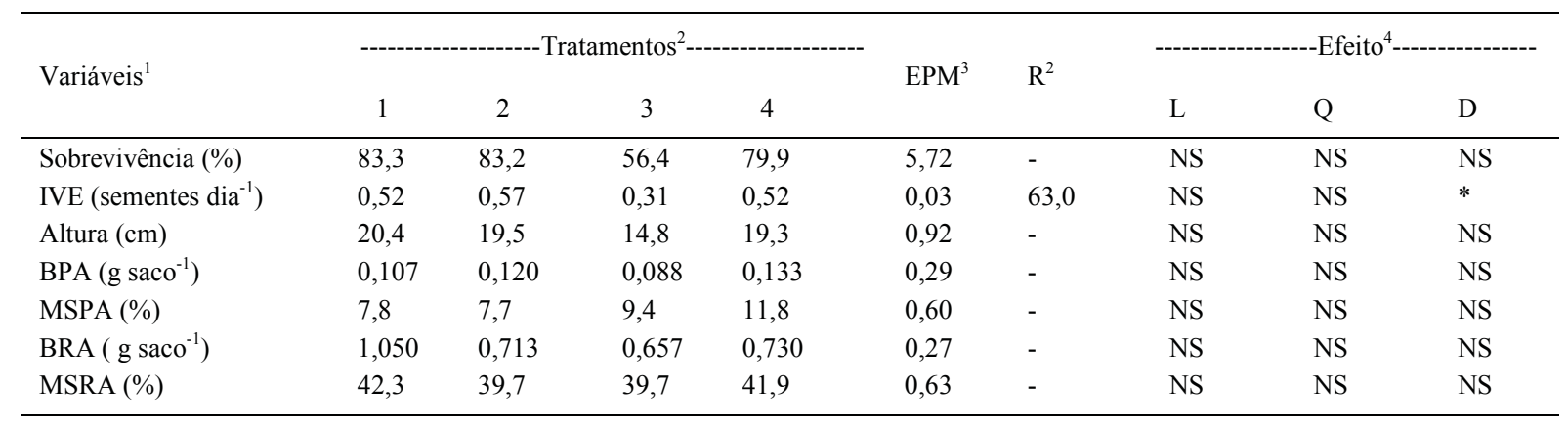


diferentes níveis de cloreto de sódio na solução nutritiva, verificaram redução da matéria seca da parte aérea e das raízes, da razão entre a parte aérea e raízes, índice de área foliar, taxa de crescimento absoluto, taxa de crescimento relativo, quando as plântulas de milho foram submetidas a uma concentração de $100 \mathrm{~mol} \mathrm{~m}^{-3}$ de $\mathrm{NaCl}$. Segundo os autores, a parte aérea é mais sensível a elevadas concentrações de $\mathrm{NaCl}$ quando comparada com as raízes.

Em estudo com sementes de milho oriundas de plantas cultivadas sob diferentes níveis de salinidade do solo, GARCIA et al. (2007) observaram que a salinidade média do solo, ao longo do período de cultivo, afetou significativamente todas as características avaliadas, reduzindo a porcentagem de germinação, velocidade de germinação e emergência, matéria seca e fresca das plântulas, seguido do aumento da porcentagem de sementes deterioradas e de plântulas anormais.

Níveis elevados de sais no solo são apontados como os responsáveis por afetar a planta inteira, diminuindo a produtividade, além de provocar a sua morte (ESTEVES \& SUZUKI, 2008). Ainda, segundo os mesmos autores, durante o efeito da salinidade, determinados processos são afetados, como a síntese de proteína, metabolismo lipídico e fotossíntese. Porém, possivelmente, esses fatores não foram afetados pela salinidade presente nos substratos, pois não se verificou efeito $(\mathrm{P}>0,05)$ sobre maior parte das variáveis fisiológicas observadas, demonstrando uma adaptação da cultivar caatingueiro à salinidade presente nos substratos, quando em estágios iniciais. Diante do exposto, o aproveitamento do esterco de ovinos alimentados com água em diferentes níveis de salinidade para o uso agrícola implica compatibilizar a produção de uma cultura com um estresse salino progressivo.

\section{CONCLUSÃO}

Esterco oriundo de ovinos alimentados com águas salinas não afeta negativamente a produção de plântulas de milho quando as concentrações de sólidos dissolvidos totais na água de beber são de até $8.326,0 \mathrm{mgL}^{-1}$, com condutividade elétrica de até 13 $\mathrm{dSm}^{-1}$. Entretanto, o aumento gradativo da salinidade implica menor índice de velocidade de emergência, se for verificada, em consequência, a deficiência de potássio no substrato.

\section{AGRADECIMENTOS}

Ao Programa Água Doce do Ministério do Meio Ambiente e ao Conselho Nacional de Desenvolvimento Científico e Tecnológico (CNPq).

\section{REFERÊNCIAS}

ALVES, F.S.F.; PINHEIRO, R.R. O esterco caprino e ovino como fonte de renda. Brasília: Embrapa, 2008. Disponível em: $<$ http:// www.agricultura.gov.br>. Acesso em: 12 jun. 2012.

ARAUJO, W.B.M. de et al. Esterco caprino na composição de substratos para formação de mudas de mamoeiro. Ciência e Agrotecnologia, v.34, n.1, p. 68-73, jan./ fev., 2010. Disponível em: $<$ http://www.scielo.br/scielo.php?script=sci_arttext\&pid=S14 $1370542010000100008 \& \operatorname{lng}=\mathrm{en} \& \mathrm{nrm}=\mathrm{iso}>$. Accesso em: 19 out. 2012.doi: 10.1590/S1413-70542010000100008.

BLANCO, F.F, et al. Emergence and growth of corn and soybean under saline stress. Scientia Agricola, v.64, n.5,p.451-459, 2007.

BRASIL. Ministério da Agricultura e Reforma Agrária. Regras para análise de sementes. Brasília: SNDA/DNDV/CLAV, 1992.365 p.

CERETTA, C.A. Produtividade de grãos de milho, produção de MS e acúmulo de nitrogênio, fósforo e potássio na rotação aveia preta/milho/nabo forrageiro com aplicação de dejeto líquido de suínos. Ciência Rural, v.35, n.6, p.1287-1295, 2005.

COMPANHIA NACIONAL DE ABASTECIMENTO. Levantamento da safra de grãos. 2008. Disponível em: <www. conab.gov.br>. Acesso em: 14 de jun.2012.

CONCEIÇÃO, P.M. et al. Estimativa do vigor de sementes de milho através da avaliação do sistema radicular de plântulas. Ciência Rural, v.42, n.4, p.600-606, 2012.

CONUS, L.A. et al. Germinação de sementes e vigor de plântulas de milho submetidas ao estresse salino induzido por diferentes sais. Revista Brasileira de Sementes [online], v.31, n.4, p.67-74, 2009.

CRUZ, J.C. Produção de milho na agricultura familiar. Embrapa Milho e Sorgo, 2011. 42p. (Circular Técnica, 159).

DEMARCHI, M. Análise da conjuntura agropecuária. 2012. Disponível em: <http://www.agricultura.pr.gov.br/arquivos/File/ deral/Prognosticos/milho_2011_12.pdf>. Acesso em: 9 jul. 2012.

DURÃES, F.O.M.; CHAMMA, H.M. Índices de vigor de milho: associação com emergência em campo, crescimento e rendimento de grãos. Revista Brasileira de Sementes, v.17, n.1, p.13-18, 1995.

ESTEVES, B.S.; SUZUKI, M.S. Efeito da salinidade sobre as plantas. Oecologia Australis, v.12, n.4, p.662-679, 2008.

FAQUIN, V. Nutrição mineral de plantas. Lavras: UFLA/FAEPE, 2005. 183p.

GARCIA, G.O.; FERREIRA, P.A. Qualidade nutricional e fisiológica de sementes de milho oriundas de plantas submetidas ao estresse salino. Engenharia na Agricultura, v.15, n.3, p.281-289, 2007.

GOMES, J.A. Adubações orgânica e mineral, produtividade do milho e características físicas e químicas de um argissolo vermelho amarelo. Acta Scientiarum. BiologicalSciences, v.27. n.3, p.521529, 2005.

KONZEN, E.A. Manejo e utilização de dejetos animais: aspectos agronômicos e ambientais. Embrapa Milho e Sorgo, 2005. 16p. (Circular Técnica, 63). 
LABOURIAU, L.G.; VALADARES, M.E.B.On the germination of seeds of Calotropisprocera(Ait) Ait. f. Anais da Academia Brasileira de Ciências, v.48, n.2, p.236-284, 1976.

McGREGOR, B.A. Water quality and provision for goats. Australian Government. Rural Industries Research and Development Corporation. 19p. 2004.

MAGUIRE, J.D. Speed of germination aid in selection and evaluation for seedling and vigour. Crop Science, v.2, n.2, p.176-177, 1962.

MALAVOLTA, E. et al. Avaliação do estado nutricional das plantas: princípios e aplicações. 2.ed. Piracicaba: POTAFOS,1997. 319p.

MENGEL, K.; KIRBY, A. Principles of plant nutrition Bern:International Potash Institute, 1987. 687p.

NEGREIROS, J.R.S. et al.Diferentes substratos na formação de mudas de maracujazeiro-amarelo. Revista Ceres, v.LI, n.294, p.243249, 2004.

PRIMAVESI, A. Manejo ecológico do solo: a agricultura em regiões tropicais. São Paulo: Nobel, 1990.549p.
RODRIGUES, T.R.D.; MAI, C. Adubação orgânica no milho como forma de melhorar a sustentabilidade do sistema de produção agrícola. In: CONGRESSO BRASILEIRO DE AGROECOLOGIA,7., 2011, Fortaleza, CE. Anais...Porto Alegre: Cadernos de Agroecologia, 2011.V.6. n.2. p.1.

SAS INSTITUTE. SAS System for Windows. Version 8.0. Cary, 2003. 2 CDROMs.

SANTOS, V.L.M. et al. Efeito do estresse salino e hídrico na germinação e vigor de sementes de soja. Revista Brasileira de Sementes, v.14, n.2, p.189-194, 1992.

SANTOS, M.J.G. Crescimento e desenvolvimento de plantas de milho sob diferentes doses de esterco de galinha. 2009. 62f. Monografia (Especialização em Zootecnia)- Curso de Pós-graduação em Zootecnia, Faculdades Anhanguera de Dourados, MG.

VIANA, J.S. et al. Emergência e crescimento de plântulas de milho procedentes de sementes produzidas em sistemas de manejo de solo com e sem adubação mineral. Revista Ciência Agronômica, v.36, n.3, p.316-321, 2005. 